\title{
Evaluating of the Mental Foramen Region Based on CBCT
}

\author{
Cao Kun, Li Jiafeng*, Bao Qiang, Lv Zhongjing, Lu Qiuning \\ Department of Oral and Maxillofacial Surgery, the Affiliated Hospital of Xuzhou Medical University, Xuzhou, China \\ Email address: \\ jiafengli203@163.com (Li Jiafeng), kellyi@126.com (Cao Kun) \\ ${ }^{*}$ Corresponding author
}

\section{To cite this article:}

Cao Kun, Li Jiafeng, Bao Qiang, Lv Zhongjing, Lu Qiuning. Evaluating of the Mental Foramen Region Based on CBCT. International Journal of Clinical Oral and Maxillofacial Surgery. Vol. 5, No. 1, 2019, pp. 1-4. doi: 10.11648/j.ijcoms.20190501.11

Received: December 20, 2018; Accepted: January 11, 2019; Published: February 19, 2019

\begin{abstract}
Objective: The aim of this study was to measure and evaluate the bone anatomy morphology in mental foramen area using cone-beam computed tomography (CBCT). Methods: CBCT images of 100 patients were retrospective studied and measured. The anatomy morphology and adjacency of mental foramen, mental canal and mandibular canal were observed and measured. All the dates were analyzed by statistical package of SPSS17.0 software. Results: The anterior terminal part of the mandibular canal divided into mental canal and incisor nerve canal, 87.5\% mental canal bended backward, upward and outward then opened to the mental foramen. The average distance from the superior border of mental foramen to the alveolar crest was $(12.9 \pm 1.28) \mathrm{mm}$, and from the anterior border of mental foramen to the anterior end of mandibular canal was $(3.6 \pm 1.14) \mathrm{mm}$, and from the inferior border of mental foramen to the superior border of mandibular canal was $(3.9 \pm 0.97)$ mm, and from the superior border of mental foramen to the superior border of mental canal was $(1.4 \pm 0.42) \mathrm{mm}$. Conclusions: CBCT can reflect the bone anatomy morphology of mandible accurately, and the safe distance from the tip of implant to the mental foramen should be re-evaluated.
\end{abstract}

Keywords: Mandible, Mental Canal, Mental Foramen, Cone-Beam Computed Tomography (CBCT)

\section{Introduction}

In recent years, with the development of dental implantation, the anatomical structure of mental foramen has been paid more and more attention. In the past, the anterior mental foramen area was considered as a relatively safe area for implantation surgery, and more and more studies have found that implantation surgery in the anterior mental foramen area can also lead to neurological damage, hemorrhage and other complications, and even lead to the failure of the operation. Accurate preoperative analysis and design can reduce the occurrence of these complications. CBCT can accurately reflect the bone anatomy morphology of mandible, which can improve the safety and success rate of implantation in the mental foramen area. The purpose of this study was to measure and evalute the anatomic structure of mental foramen area with CBCT, so as to provide references for the smooth development of implant operation in this area.

\section{Materials and Methods}

\subsection{Material}

A total of 100 patients with CBCT were selected from the affiliated hospital of Xuzhou medical university from September 2015 to May 2016. There were 56 males and 44 females aged from 18 to 76 years, with an average age of 43 years. Inclusion criteria: 1 . The reconstruction image of mental foramen CBCT is complete and clear; 2. No supernumerary teeth or impacted teeth; 3. No history of surgical trauma such as fracture; 4. No space occupying lesions.

\subsection{Method}

\subsubsection{CBCT Image Acquisition}

All patients were seated with both eyes facing forward, without speaking, chewing and swallowing, with the head positioned symmetrically and keeping the Frankfort plane 
parallel to the ground. Equipment: KaVo 3D eXam I (USA), Invivo Dental Demo software. Scan range: $14 \mathrm{~cm} * 8.5 \mathrm{~cm}$, $360^{\circ}$ full scan. Scanning parameters: layer thickness $0.2 \mathrm{~mm}$, scanning time $23 \mathrm{~s}$, working voltage $120 \mathrm{kVp}$, current $30.89 \mathrm{mAs}$. The output datas were stored in Dicom format.

\subsubsection{Image Analysis and Measurement}

The obtained Dicom format data were reconstructed by Invivo5 software, the contrast and gray values were adjusted. The images were cut in sagittal, coronal and cross-section, and coronal and oblique sagittal images were selected to measure relevant data. Measurement method: the vertical distance from the upper edge of mental foramen to the alveolar crest was measured on the panoramic image (A), the horizontal distance from the front edge of mental foramen to the front end of the mandibular canal (B), and the vertical distance from the lower edge of the mental foramen to the upper edge of the mandibular canal $(\mathrm{C})$. The vertical distance $(\mathrm{H})$ between the inner edge of mental foramen and the upper edge of mental canal was measured on the oblique sagittal image (Figure 1 and Figure 2). All data were measured twice, and the measurement interval was 2 weeks or more, then the average was taken.

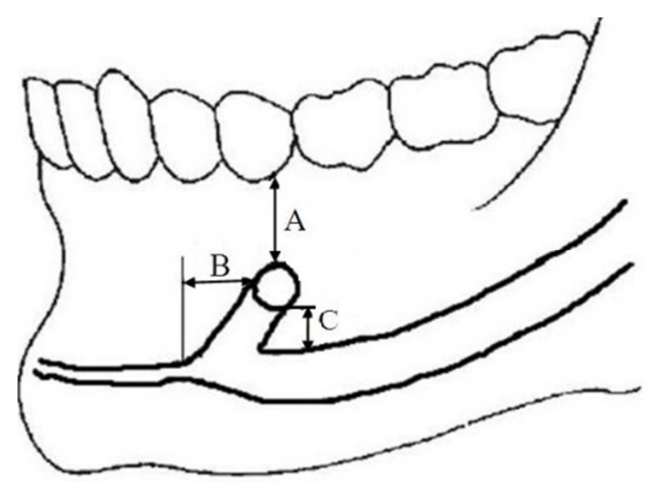

Figure 1. Coronal level measurement of mental foramen.

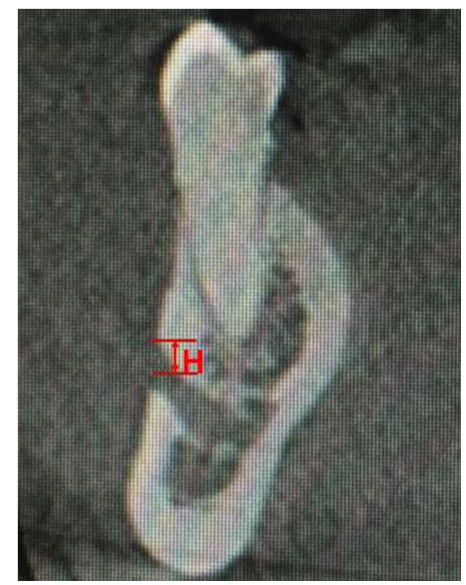

Figure 2. Oblique sagittal level measurement of mental foramen.

\subsubsection{Statistical Analysis}

SPSS17.0 statistical software was used for statistical analysis of the measured data. The difference between the gender group and the mental foramen area with and without teeth was tested by independent $\mathrm{t}$ test, and $\mathrm{P}<0.05$ was statistically significant.

\section{Results}

\subsection{Distribution of Mental Foramen in the Mandible}

It was found that the position of mental foramen was most commonly seen in the root of the second premolar of the mandible $(58 \%)$, followed by the root between the first and second premolar $(31 \%)$, and the root between the second premolar and the first molar (7\%), which was rarely seen in the first premolar and the first molar (table 1).

Table 1. Distribution of mental foramen.

\begin{tabular}{lllll|ll|l}
\hline & $\overline{\mathbf{4}} \mid \mathbf{4}$ & $\overline{\mathbf{5 4}}$ & $\mathbf{4 5}$ & $\overline{\mathbf{5}} \mid \mathbf{5}$ & $\overline{\mathbf{6 5}} \mid \mathbf{5 6}$ & $\overline{\mathbf{6}}$ & $\mathbf{6}$ \\
\hline Case & 5 & 62 & 116 & 14 & 3 \\
Percentage (\%) & 2.5 & 31 & 58 & 7 & 1.5 \\
\hline
\end{tabular}

\subsection{Positional Relationship of Mental Foramen, Mental Canal and Mandibular Canal}

The mandibular canal was divided into mental canal and incisor canal, the mental canalbended backward, upward and outward then opened to the mental foramen (87.5\%, Figure 3$)$, while another 18 cases were opened upward and outward to the mental foramen (Figure 4), and 7 cases were directly outward to the mandible surface (Figure 5), the nerve bundle was passed through the mental canal.

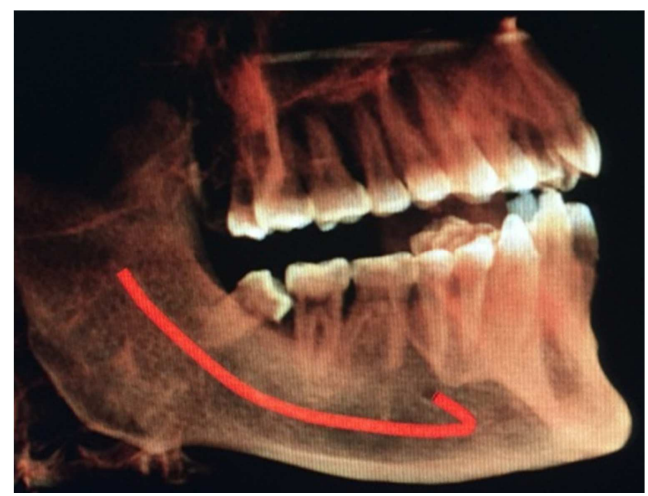

Figure 3. The mental canalbended backward, upward and outwardthen opened to the mental foramen.

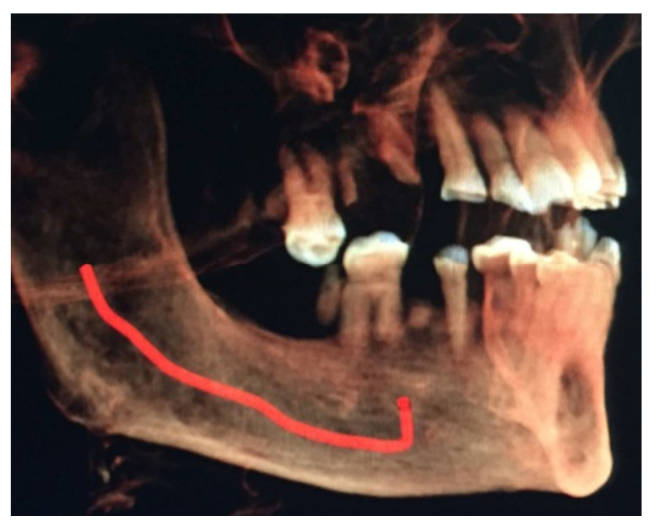

Figure 4. The mental canal opened upward and outward to the mental foramen. 


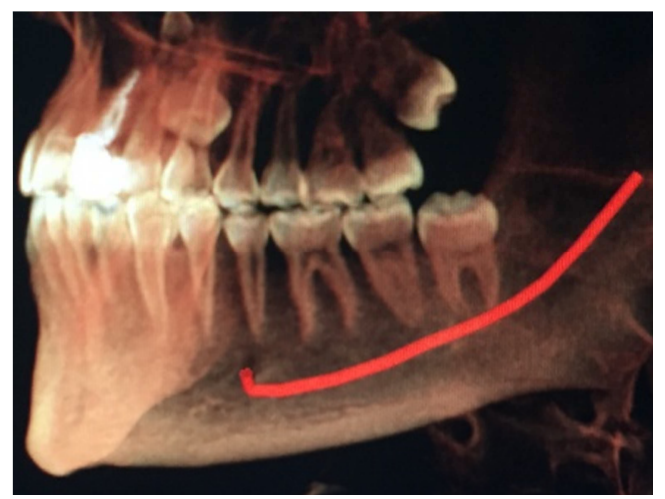

Figure 5. The mental canal directly outward to the mandible surface.

In the mental foramen area, the vertical distance (A) from the upper edge of the mental foramen to the alveolar crest is $(12.9+1.28) \mathrm{mm}$, the horizontal distance $(\mathrm{B})$ from the front edge of the mental foramen to the tip of the mandibular canal is $(3.6+1.14) \mathrm{mm}$, the vertical distance $(\mathrm{C})$ from the lower edge of the mental foramen to the upper edge of the mandibular canal is $(3.9+0.97) \mathrm{mm}$, and the vertical distance (D) from the inner edge of the mental foramen to the upper edge of the mental canal is $(1.4+0.42) \mathrm{mm}$ (table 2$)$.

Table 2. Positional relationship of mental foramen, mental canal and mandibular canal.

\begin{tabular}{lllll}
\hline \multicolumn{5}{c}{ Measurement item } \\
\cline { 2 - 5 } & $\mathbf{A}$ & $\mathbf{B}$ & $\mathbf{C}$ & H \\
\hline Min & 7.9 & 0 & 2.4 & 0.41 \\
$\operatorname{Max}$ & 13.8 & 6.9 & 7.1 & 2.91 \\
$\overline{\boldsymbol{X}} \pm S$ & $12.9 \pm 1.28$ & $3.6 \pm 1.14$ & $3.9 \pm 0.97$ & $1.4 \pm 0.42$ \\
\hline
\end{tabular}

\subsection{Statistical Analysis}

The comparison of measurement results in genders, right and left mental foramen with or without teeth are shown in table 3. Among them, the differences of gender and left-right contrast were no statistically significant, and the difference of the vertical distance from the upper edge of mental foramen to the alveolar crest was statistically significant in the groups with and without teeth, $\mathrm{P}=0.01$.

Table 3. Comparison of difference of measurement results in mental foramen area.

\begin{tabular}{lllllll}
\hline \multirow{2}{*}{ item } & gender & & \multicolumn{3}{c}{ with and without teeth } \\
\cline { 2 - 5 } & male & female & P & have teeth & no teeth \\
\hline A & $13.1 \pm 1.46$ & $12.8 \pm 1.53$ & 0.49 & $14.2 \pm 2.11$ & $9.1 \pm 2.04$ \\
B & $3.6 \pm 1.21$ & $3.5 \pm 1.18$ & 0.11 & $3.6 \pm 1.08$ & $3.6 \pm 0.97$ \\
C & $3.9 \pm 1.07$ & $3.8 \pm 1.12$ & 0.06 & $3.8 \pm 0.96$ & $3.9 \pm 1.14$ \\
H & $1.5 \pm 0.42$ & $1.4 \pm 0.42$ & 0.71 & $1.4 \pm 0.40$ & 0.01 & $1.4 \pm 0.48$ \\
\hline
\end{tabular}

\section{Discussion}

Williams et al [1] proposed the concept of mental canal earlier, but there was always error in understanding of mental canal in domestic anatomy books [2]. Previously, it was considered that it was relatively safe to avoid the mental foramen or to perform the operation in the mesial of the mental foramen. However, as more and more studies have confirmed, the mental canal is the branch of the mandibular canal going backward and outward in the anterior molar area, the safe distance of the implantation should be re-evaluated [3].

The morphological analysis of jaw bone depends on anatomical specimens and auxiliary examination tools. Anatomic specimen study affects the reliability of the study results in terms of quantity, accuracy of specimen evaluation and measurement error [4]. Traditional imaging methods, such as X-ray and spiral $\mathrm{CT}$, fail to show the spatial relationship between important anatomical structures in two-dimensional images, and the limitations of these methods can lead to information distortion [5]. Laster [6] concluded that many of the results were not reliable even after the measurement data were corrected when the oral panoramic image was used for measurement analysis. The emergence of CBCT has solved these problems. CBCT can be used to accurately display the important anatomical structure and spatial relationship of the jaw bones in the three-dimensional reconstruction of the jaw image. Moreover, CBCT scanning has a short time, low radiation dose $(1 / 30 \sim 1 / 100$ of spiral CT) [7], accurate positioning, and is especially suitable for the examination and diagnosis, which is of general clinical significance for oral implantation. In this paper, the anatomy of mental foramen area was measured and analyzed by $\mathrm{CBCT}$, providing reference for clinical work.

The position of mental foramen varies from person to person [8-10]. It was found that the mental foramen position was mainly located in the second premolar root, followed by the first and second premolar root $[11,12]$. This study found that the position of the mental foramen was most common in the root of the second premolar, which was consistent with the previous research results of Jinzhukun et al [13]. Wang fang [14] and Tian hua et al [15]. found that the opening direction of mental foramen was mostly backward, upward and outward, and some openings were upward or outward perpendicular to the surface of the mandible. Our study found that the mental canal appearance rate was $100 \%$, the distance from mental foramen front edge to the mandibular canal front was $(3.6+$ 1.14) $\mathrm{mm}$, from the superior border of mental foramen to alveolar crest was $(12.9+1.28) \mathrm{mm}$, there was no statistical significance difference in gender and left-right contrast $(\mathrm{P}>$ $0.05)$, hole crest distance in comparison with and without teeth difference is statistically significant $(\mathrm{P}=0.01)$, the results were similar to Farrugia MK etc [16].

In previous studies, due to the ignorance of the existence of the mental canal, it has been considered that the bilateral mental cananl is the safe area of the mandible. The clinical application of CBCT has attracted the attention of many 
scholars. Some scholars suggested that the implantation operation in the pre-mental area should be at least $5 \mathrm{~mm}$ away from the front edge of the mental foramen in order to ensure the mental nerve bundle is not damaged [17], and the distance from the upper edge of the mental foramen should be no less than $2 \mathrm{~mm}$ [18]. This study based on 100 patients with bilateral mental foramen area CBCT images were observed and measured, found that inferior alveolar nerve after to the mental foramen area on the outside direction through the formation of mental nerve, the average distance from mandibular canal upper edge to mental foramen lower edge was $(3.9+0.97) \mathrm{mm}$, moreover the average distance from $1.5 \mathrm{~mm}$ inside the upper edge of mental foramen to mental canal was $(1.4+0.42) \mathrm{mm}$, according to at least $1.5 \mathrm{~mm}$ bone plate and $2 \mathrm{~mm}$ safety distance on the neural canal should be preserved on the buccal-lip side of implant [19], The tip of the implant on the posterior edge of the mental foramen can be placed under the upper edge of the mental foramen by $4 \mathrm{~mm}$, while the tip of the implant perpendicular to the upper edge of the mental foramen can be placed on the mental foramen by $0.5 \mathrm{~mm}$. Under the condition that the nerve is not damaged, the length of the implant is increased, improving the initial stability of the implant and the satisfaction of long-term clinical results. In addition, the study of the anatomical structure of the mental foramen also provides a clinical reference for "all-on-4" edentulous implantation [20].

\section{Conclusion}

In summary, this study used $\mathrm{CBCT}$ to measure anatomical structure of mental foramen area, and gives recommendations for the safe range of implant operation in this area, but there are anatomical variations, to ensure absolute safety, it is best to perform $\mathrm{CBCT}$ examination before preoperative, and personalized design based on the results.

\section{References}

[1] Williams PL, Warwick R. Grays Anatomy [M]. 36th ed. Philaelphia: Saunders, 1980:316.

[2] Yu Pin. Systematic anatomy [M]. BeiJing: People's Medical Publishing House. 1996. 288.

[3] Marilza D C O, Tedesco T K, Gimenez T, et al. Analysis of the frequency of visualization of morphological variations in anatomical bone features in the mandibular interforaminal region through cone-beam computed tomography [J]. Surgical and Radiologic Anatomy, 2018, 40 (10):1119-1131.

[4] Wu Yinzhou, Hu Shengwang. Observation and Measurement of Mandibular Canal and Distance from it to Alveolar Ridge Crysta Study with100Cases of Mandibale [J]. Chinese Journal of Oral Implantology, 2005, 10 (1):180-181.

[5] Aminoshariae A, Su A, Kulild J C. Determination of the Location of the Mental Foramen: A Critical Review [J]. Journal of Endodontics, 2014, 40 (40):471-475.

[6] Laster W S, Ludlow J B, Bailey L J, et al. Accuracy of measurements of mandibular anatomy and prediction of asymmetry in panoramic radiographic images. [J]. Dentomaxillofacial Radiology, 2005, 34 (34):343-9.

[7] Ngan D C, Kharbanda O P, Geenty J P, et al. Comparison of radiation levels fromcomputed tomography and conventional dental radiographs [J]. Australian orthodonticjournal, 2003, 19 (2): 67-75.

[8] Çağlayan F, Sümbüllü M A, Akgül H M, et al. Morphometric and morphologic evaluation of the mental foramen in relation to age and sex: an anatomic cone beam computed tomography study. [J]. Journal of Craniofacial Surgery, 2014, 25 (6):2227-2230.

[9] Fujita A, Suzuki T. Computed tomographic analysis of the mental foramen and nerve in Japanese patients. [J]. Implant Dentistry, 2014, 23 (4):471-6.

[10] Sadrameli M. Anatomic Considerations in Dental Implant Surgery [J]. 2017, 57-78.

[11] $2 \mathrm{Nd} \mathrm{S} \mathrm{W}$. The position of the mental foramen in Asian Indians. [J]. Journal of Oral Implantology, 1994, 20 (2):118-23.

[12] Aureli F. The Mental Foramen I: Radiographic Study of the Anterior-Posterior Position and Shape in Iraqi Population [J]. Philosophical Transactions of the Royal Society a Mathematical Physical \& Engineering Sciences, 2015, 360 (1794):859-74.

[13] JIN Zhukun, LI Xiao, YANG Kai. Position of mandibular canal determined by spiral CT examination in 68 Chinese people [J]. Journal of Practical Stomatology, 2013, 29 (4):495-499.

[14] Wang Fang, Pan Juli, Li Yidan, et al. The applied anatomicaI study of mentaI canal [J]. Journal of Practical Stomatology, 2004, 20 (4):463-465.

[15] TIAN Hua, WANG Jianhua, YIN Qunsheng, et al. Morphological characteristics of mental canal and its clinical significance [J]. Chinese Journal of Clinical Anatomy, 2001, 19 (3):215-216.

[16] Farrugia M K, Melville D, Boddy S A. Location and Dimensions of the Mental Foramen: A Radiographic Analysis by Using Cone-beam Computed Tomography. [J]. Journal of Endodontics, 2013, 39 (12):1522-8.

[17] Uchida Y, Noguchi N, Goto M, et al. Measurement of anterior loop length for themandibular canal and diameter of the mandibular incisive canal to avoid nerve damage when installing endosseous implants in the interforaminal region: a second at temptintroducing cone beam computed tomography [J]. Journal of Oral and Maxillofacial Surgery, 2009, 67 (4): 744-750.

[18] Greenstein G, Tarnow D. The mental foramen and nerve: clinical and anatomical factorsrelated to dental implant placement: a literature review [J]. Journal of periodontology, 2006, 77 (12): 1933-1943.

[19] Sener E, Onem E, Akar G C, et al. Anatomical landmarks of mandibular interforaminal region related to dental implant placement with 3D CBCT: comparison between edentulous and dental mandibles [J]. Surgical and Radiologic Anatomy, 2017, 40 (6):615-623.

[20] Alex M. Greenberg, Leslie H. Sultan. Clinical Cone Beam CT and CT-Guided Dental Implant Surgery [J]. Digital Technologies in Craniomaxillofacial Surgery, 2018, 67-116. 